\title{
Julio Herrera y Reissig: poesia com pedal
}

André Fiorussi ${ }^{a}$

\section{Resumo}

Em notas que escreveu para explicar soluções adotadas na tradução de dois poemas franceses, o poeta uruguaio Julio Herrera y Reissig (1875-1910) defende o uso da "diérese silenciada" e toma-o como ponto de partida para uma ampla exposição de uma nova música do verso, constituída por uma série de recursos capazes de promover, em conjunto, uma nova música para a poesia em língua espanhola. Este artigo propõe que as notas de Herrera y Reissig sobre o tema cumprem uma função tática que vai muito além da discussão técnica e normativa, e podem ser interpretadas como uma preceituação e uma descrição da música da chamada poesia modernista hispano-americana. As notas ensejam a percepção de que o ritmo poético não está plenamente inscrito no texto, como tampouco independe dele: produzse historicamente em construtos complexos, nos quais interferem diversos membros de uma sempre dinâmica comunidade que inclui poetas, leitores, editores, preceptistas.

Palavras-chave: Julio Herrera y Reissig (18751910), diérese silenciada, Modernismo hispanoamericano, Música e poesia, ritmo.

Recebido em 30 de março de 2016 Aceito em 16 de junho de 2016

a Professor Adjunto de Literaturas Hispânicas no Departamento de Língua e Literatura Estrangeiras da UFSC, fiorussi@gmail.com. 
Ao comparar versos alexandrinos do uruguaio Julio Herrera y Reissig (1875-1910) com outros do romântico espanhol Zorrilla, o crítico Mario Alvarez (1995, p. 119-20) escreve: “À tonicidade inapelável de Zorrilla, que funciona como golpes que pautam um ritmo, corresponde em Herrera uma tonicidade discreta, até vacilante: o poeta usa o pedal". A analogia é precisa: consegue mostrar aos ouvidos do leitor as sutilezas musicais do verso de Herrera y Reissig, e instrui, por extensão, a leitura de outros poetas do chamado modernismo hispano-americano. Afinados com a perseguição oitocentista de uma aliança com a música, os poetas modernistas exploraram novas formas métricas e rítmicas e promoveram uma revolução nos hábitos de leitura e nos critérios de apreciação poética na América e na Espanha. Com uma obra em muitos aspectos singular e ainda pouco conhecida no Brasil, Herrera y Reissig se destaca entre os modernistas pelos efeitos marcantes que produz tanto no plano semântico e simbólico quanto também no musical. Este artigo pretende estudar uma das técnicas empregadas e preceituadas por Herrera y Reissig para potencializar o caráter musical dos versos: a "diérese silenciada", responsável em grande medida por um efeito de instabilidade sonora análogo ao que havia produzido o pedal de sustentação na música romântica.

Segundo o musicólogo Charles Rosen, "poucos meios serão melhores para se compreender a revolução estilística promovida pelo século XIX que o exame do modo pelo qual os compositores requisitaram o pedal de sustentação" (ROSEN, 2000, p. 41). Usado na música clássica como apoio ornamental à execução de determinadas características de uma composição, o pedal passa, com os românticos, de exceção a regra:

Na escrita da geração romântica de 1830, a pedalização completa se torna, de fato, norma: espera-se, do piano, que ele soe de maneira bastante constante: uma sonoridade sem pedal é uma exceção, quase um efeito especial. Além disso, a frase é agora modelada, ao menos parcialmente, por alterações dessa vibração total. A mudança de pedal é crucial com relação ao movimento rítmico e à sustentação da linha melódica do baixo. (ROSEN, 2000, p. 56)

O pedal de sustentação é aquele que permite, fundamentalmente, o prolongamento das notas tocadas. $\mathrm{O}$ pedal ergue os abafadores das cordas do piano, permitindo 
assim que elas sigam vibrando após a soltura das teclas correspondentes. Além do prolongamento, há então um segundo efeito básico do pedal: sem contato com os abafadores, as cordas não acionadas também vibram, produzindo uma sutil nuvem de sons que altera sensivelmente a sonoridade da música executada. Seu acionamento e soltura podem ser feitos gradualmente, o que permite uma vasta gama de intensidades de uso, principalmente no que se refere à retirada das notas. Assim, não é apenas a duração de certas notas que se modifica com o uso do pedal de sustentação: timbre, harmonia, ritmo, todos os elementos da música podem ser afetados, em maior ou menor grau, por esse mecanismo.

Chopin, Liszt e Schumann são alguns dos compositores que, segundo Rosen, impõem um uso cada vez mais extensivo e complexo do pedal de sustentação. De Chopin, por exemplo, Rosen escreve que "o novo estilo [...] e a extraordinária sonoridade que ele, pela primeira vez, criou, dependem sobretudo de uma nova e original utilização do pedal" (ROSEN, 2000, p. 53). Mais do que sugeri-lo como ornamento, as partituras românticas passam a exigi-lo constantemente como meio rigorosamente indispensável para a execução, contendo indicações precisas e muitas vezes curiosas. Rosen exibe exemplos nos quais Chopin indica que o pedal deve ser acionado em momentos diferentes na execução de sequências repetidas, fazendo com que duas melodias simultâneas e idênticas se relacionem entre si de modos diferentes, através do pedal, na primeira e nas outras vezes em que ocorrem. Schumann, que segundo Rosen usa o pedal de forma ainda mais audaciosa, chega a indicar em uma partitura, por exemplo, que o recurso deve ser acionado não para prolongar notas que serão golpeadas, mas apenas para modificar a ressonância de notas anteriores ainda em vibração (ROSEN, 2000, p. 57).

Rosen oferece diversos exemplos em que o emprego do pedal tem efeitos sobre o ritmo, articulando, através das ressonâncias que ele ativa, fragmentos que de outro modo pareceriam independentes, e agindo, pode-se dizer, na coesão dos sons, na passagem de um a outro compasso, na constituição de frases, na acentuação etc. Nesse sentido é que se pode explorar melhor a analogia de Mario Alvarez entre a sonoridade dos versos de Herrera y Reissig e o uso do pedal no piano: por meio de técnicas verbais ligadas ao prolongamento 
de sílabas, à repetição de sons vocálicos e consonantais, a ecos, reverberações e paronomásias, o poeta é capaz de produzir ritmos ambíguos, flutuantes e sugestivos; além disso, como veremos, ele pode inscrever na própria estrutura dos versos alguns aspectos que se deveria esperar da performance, ou seja, alguns elementos que normalmente cumpririam apenas à declamação em voz alta. Observemos um dos efeitos de pedal praticados por Herrera y Reissig: a diérese silenciada.

O termo diérese designa um recurso poético de alongamento silábico que consiste em transformar um possível ditongo em hiato. Tradicionalmente, em espanhol (como em português), a diérese pode ser indicada pelo sinal diacrítico do duplo ponto (trema) sobre a vogal prolongada. Observem-se alguns exemplos na poesia do nicaraguense Rubén Darío (18671916), principal figura do Modernismo hispano-americano, que transcrevemos a partir da edição crítica de Alfonso Méndez Plancarte (1968):

Rodrigo de Bivar pasa, meditabundo,

Por una senda en donde, bajo el sol glorïoso,

Tendiéndole la mano, la detiene un leproso.

(DARÍO, 1968, p. 606)

Ese es mi mal. Soñar. La poesía

Es la camisa férrea de mil puntas crüentas

Que llevo sobre el alma [...]

(DARÍO, 1968, p. 675)

Y vi azul y topacio y amatista,

Oro y perla y argento y vïoleta [...]

(DARÍO, 1968, p. 713)

Rosa de dolor, gracia femenina;

Inocencia y luz, corola divina,

Y aroma fatal y crüel espina...

(DARÍO, 1968, p. 663)

Recebem diérese, respectivamente, as palavras glorioso, crüentas, vïoleta e crüel, que devem ser lidas glo-ri-o-so, cru-entas, vi-o-le-ta, cru-el; do contrário, faltaria uma sílaba ao metro. Vale notar que, no penúltimo exemplo, o desmembramento da 
primeira sílaba de violeta cria uma sílaba forte "vi" que repete o verbo monossílabo do início do verso anterior ( $Y \underline{v i}$ azul...), implícito entre todas as visões nomeadas.

Tradicionalmente, a diérese é tratada como uma licença poética, para a qual conhecidos manuais de versificação do século XIX prescrevem um uso parcimonioso. Em português, encontra-se esse tipo de advertência, por exemplo, no Tratado de Metrificação Portuguesa (1851) de Antônio Feliciano de Castilho; mais tarde, no Brasil, Olavo Bilac e Guimarães Passos reproduziram o conselho em seu Tratado de versificação (1905). Em espanhol, a mais conhecida Arte de hablar en prosa y verso do século XIX é a de José Gómez de Hermosilla (1826) - celebrizada em seu tempo por ter sido adotada oficialmente como instrumento pedagógico na Espanha e na América, e no fim do século por ter se tornado o principal alvo dos ataques modernistas (sobretudo de Rubén Darío) contra o academicismo. Nela, a diérese é tratada como a terceira de três licenças ou figuras prosódicas (sendo as outras duas a sinalefa, união em uma só sílaba de vogais contíguas pertencentes a palavras diferentes, e a sinérese, união de vogais contíguas que poderiam ser pronunciadas com hiato). Hermosilla prescreve que o uso das três licenças seja raro, e conclui a seção com o seguinte juízo:

[...] en general el verso en que no hay ninguna de las tres, es mas armonioso; el que tuviese las tres juntas, seria detestable; el que reuniese las dos últimas, ó la primera y alguna de las otras, ó muchas sinalefas, duro y arrastrado, á no ser que en cualquiera de estos casos se construya así expresamente para hacerle imitativo. (HERMOSILLA, 1826, p. 122)

Além de contrariar a regra da parcimônia, a novidade defendida por Julio Herrera y Reissig consiste em silenciar a diérese, isto é, não usar o diacrítico, como fez nos seguintes versos (com grifos nossos):

Un cielo bondadoso y un céfiro tierno...

(HERRERA Y REISSIG, 1998, p. 18)

Y en brutos sobresaltos, como ante una imprevista

Emboscada, el torrente relinchando rueda.

(HERRERA Y REISSIG, 1998, p. 33) 
Cien iluminaciones, en fluidos estambres,

Perlan de rama en rama, lloran de los alambres...

(HERRERA Y REISSIG, 1998, p. 33)

Y el mundo se pobló con el ruido

Del llanto de la fuente del paseo.

(HERRERA Y REISSIG, 1998, p. 334)

Toda duda y todo arcano

Irritaban su fiebre

(HERRERA Y REISSIG, 1998, p. 377)

O recurso é sutil, e seu uso é pouco frequente nos versos do próprio autor. Difícil falar aí em revolução poética - pensase, no máximo, em um artigo a incluir numa proposta de reforma. Não obstante, em duas notas de rodapé que escreveu para explicar soluções adotadas na tradução de dois poemas franceses, Julio Herrera y Reissig toma a diérese silenciada como ponto de partida para uma ampla defesa da nova música do verso, a qual pode ser interpretada como uma preceituação e uma descrição da música da poesia modernista. A primeira das notas se refere à tradução que Herrera y Reissig fez do poema "Le Sommeil de Canope", de Albert Samain. O texto resultante, "El sueño de Canope", foi publicado em 1903 no Almanaque Artístico del Siglo XX (cf. HERRERA Y REISSIG, 1998, p. 430, nota 8), com uma curiosa observação inicial: “Traducción perfecta", além da longa nota de rodapé que transcreveremos logo adiante. A diérese silenciada aparece sete vezes num total de 34 versos. Seguem os versos iniciais do poema de Samain e da tradução de Herrera y Reissig:

Accoudés sur la table et déjà noyés d'ombre,

Du haut de la terrasse à pic sur la mer sombre,

Les amants, écoutant l'éternelle rumeur,

Se taisent, recueillis devant le soir qui meurt.

Alcis songe, immobile et la tête penchée.

(SAMAIN, 1924, p. 243)

Acodados en la mesa y en la sombra sumergidos,

Del alto terrado a pico sobre el golfo macilento, 
Los amantes, escuchando los eternales ruidos,

Ante la tarde que muere, observan recogimiento.

Alcis inmóvil sueña, con la cabeza inclinada.

(HERRERA Y REISSIG, 1998, p. 402)

Um dos entraves mais comuns à tradução de versos franceses para o espanhol (e para o português) é a falta de espaço: as doze chambres palacianas de um alexandrino francês viram quartinhos estudantis do Quartier Latin. A tendência oxítona do francês poupa sílabas, e o tradutor tem que compensar essa diferença. Já no primeiro hemistíquio do poema de Samain há um exemplo claro: accoudés ganha, em espanhol, uma sílaba átona final, acodados (a tradução literal ao português causaria um desastre métrico: "acotovelados"). O espanhol ainda tem outra dificuldade: sur la table caberia perfeitamente em "sobre a mesa", em português, porque o artigo "a" é integrado por sinalefa à sílaba final de "sobre"; em espanhol, o "l" inicial do artigo (la) impediria a sinalefa - por isso o tradutor trocou a preposição de sur la table por en la mesa.

Diante dessas dificuldades, é comum adotar em traduções para o espanhol um metro mais longo do que o original francês. Herrera y Reissig escolheu, para traduzir os alexandrinos franceses de doze sílabas, não o alexandrino castelhano (que tem 14), mas um metro ainda mais longo, de 16, composto por dois membros de oito. Assim se pode escandir, por exemplo, o primeiro verso ("Acodados en la mesa y en la sombra sumergidos"):

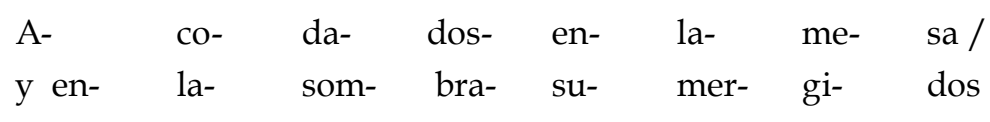

Por paralelismo, essa grade instituída pelo primeiro verso demanda que, no terceiro ("Los amantes, escuchando los eternales ruidos"), a diérese silenciada quebre o ditongo da palavra ruido:

$\begin{array}{llllllll}\text { Los- } & \text { a- } & \text { man- } & \text { tes,- } & \text { es- } & \text { cu- } & \text { chan- } & \text { do / } \\ \text { los- } & \text { e- } & \text { ter- } & \text { na- } & \text { les- } & \text { ru- } & \text { i- } & \text { dos }\end{array}$

Do contrário, não apenas faltaria uma sílaba na contagem, como também - e este é o fator mais imediatamente audível da necessidade da diérese - o último acento do segundo 
hemistíquio seria atraído para uma posição anterior à do primeiro (com grifos nossos):

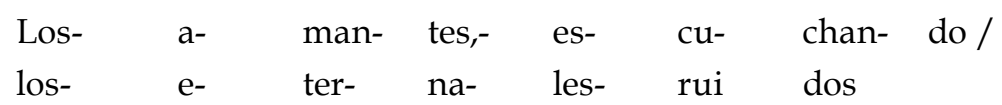

O mesmo acontece no primeiro hemistíquio do quinto verso ("Alcis inmóvil sueña, con la cabeza inclinada"), com o verbo sueña:

$\begin{array}{llllllll}\text { Al- } & \text { cis- } & \text { in- } & \text { mó- } & \text { vil- } & \text { su- } & \text { e- } & \text { na, / } \\ \text { con- } & \text { la- } & \text { ca- } & \text { be- } & \text { za in- } & \text { cli- } & \text { na- } & \text { da }\end{array}$

Há outros cinco versos da tradução em que, de acordo com o mesmo princípio, ocorre a diérese silenciada (com grifos nossos):

Por puntos sobre la puerta un resplandor trasciende;

Y el misterioso suspiro que hacia la noche asciende

[...]

El pleamar y la estrella que, en su base, se estremece

[...]

Todo lo exalta! Una lenta embriaguez de ventura

[...]

A lo lejos los follajes zumban... La noche sueña...

(HERRERA Y REISSIG, 1998, p. 402-3)

Com os exemplos, cremos que a presença do que Herrera y Reissig chama de diérese silenciada já está bem clara; mas vale ainda discutir, antes da nota de rodapé, alguns efeitos que ela provoca por reverberação. No dístico que rima trasciende e asciende, a diérese é nítida no primeiro verso; mas, no segundo hemistíquio do segundo verso ("que hacia la noche asciende"), há pelo menos quatro escansões possíveis para manter em oito o número de sílabas. Ao perceber que deve quebrar ditongos em palavras não sinalizadas com o duplo ponto da diérese, por que o leitor não quebrará também as sinalefas, por exemplo? As regras castiças podem ter sido abolidas. Institui-se aí a confusão temida por Hermosilla, que o levara a julgar detestável um verso em que as licenças prosódicas aparecessem combinadas. O ritmo se torna mais ambíguo; parte da responsabilidade 
sobre a acentuação passa ao leitor, que executa a leitura dos versos mencionados como um instrumentista executa uma música. Mas, em comparação com outros versos de Herrera y Reissig que examinaremos mais adiante, isso tudo ainda tem poucos desdobramentos nesse "Sueño de Canope", em que a regularidade geral do ritmo fornece um apoio sólido à resolução de quase todas as passagens ambíguas. É o que acontece, por exemplo, com a escansão das palavras sueña e dueña nos seguintes versos:

A lo lejos los follajes zumban... La noche sueña... Alcis, los ojos al cielo, con un beso a inclinarse, Sobre la boca ha dejado rendirse el alma a su dueña; Y súbito el corazón parécele quebrantarse!

(HERRERA Y REISSIG, 1998, p. 403)

Ao fim do primeiro verso, sueña deve ser lido com diérese; ao fim do terceiro, ainda que o leitor hesite e se deixe seduzir pela semelhança das palavras, saberá, pelo ritmo, que dueña não leva diérese. Neste como noutros casos, apesar de uma certa ambiguidade, a escansão está ligada a uma pauta rítmica que o escritor embutiu na estrutura da composição sem deixar espaço para uma interpretação mais livre do leitor, a quem cumpre descobrir uma dicção dada como correta. Num trecho de sua segunda nota de rodapé sobre a diérese silenciada, que vale antecipar aqui para concluir o argumento, o autor assim justifica a ausência do diacrítico: "a mi sentir un lector culto, que se dé cuenta del arte y del refinamiento de la expresión, no necesita señales que lo adviertan del valor fónico y de las curvas que sugiere cada vocablo, luego que el Poeta los acaricia" (HERRERA Y REISSIG, 1998, p. 416).

Com todos esses pormenores técnicos, essas justificativas extensas para sílabas tão curtas e essa estranha preferência por observar ao microscópio pedacinhos de uma coisa - a poesia - que, como escreveu Justo Sierra, "deveria ser contemplada pelo telescópio" (in MEJÍA SÁNCHEZ, 1968, p. 140), a discussão da diérese silenciada é uma daquelas que levaram e seguem levando muitos leitores a identificar no Modernismo hispanoamericano uma tendência insuportável ao preciosismo e a ultrabizantinas faltas do que fazer. Mas a leitura da primeira nota de Herrera y Reissig pode desfazer essa impressão. 
Segue em transcrição integral, apesar de longa, para preservar o andamento da prosa, lembrando que ela foi publicada junto com a tradução do poema de Samain que procuramos examinar até aqui:

Note el lector la elasticidad harmónica que doy a las palabras. Una de las conquistas modernas de la literatura quintaesente ha sido la de convertir la vieja plancha broncina, el pedrusco de la catapulta épica, que tanto gusta a los españoles y a los grafómanos del Continente, en terciopelos del pentágrama, en deslizamientos de hora crepuscular, que traducen la morbidez y el abandono anímico del poeta en las situaciones de sueño, de vacío inconsolable, de compenetración sobrehumana con la Naturaleza, de anonadamiento en las nostalgias brumosas de una vida anterior o ultraterrestre... La dulzura d'Annuncista, nacida en las fuentes soñadoras del París poético, sugiere, encanta, convierte la palabra en un murmurio, en un eco de crujía, en un pisar galante sobre pieles embrujadas, en el palacio de Monsieur Satán: en un suspiro sacrificado sobre un abanico. Y no es esto solo, sino la interpretación orquestal de todas las insinuaciones y correspondencias en la soledad, cabe el tilo de los sueños, en la playa sonora, junto a la ermita de la montaña. La diéresis silenciada es, pues, el sereno encanto, el alma de moaré de la música del verso. El gran Samain, así lo comprendió, y todas sus poesías nos muestran ese alargamiento aristocrático de la palabra, que como una liga voluptuosa rodea suavemente la pierna augusta, de arco rítmico, de Sapho, la eterna Sapho, el Mito de la Poesía, la diosa de los sueños, la virgen y la hetaira, mi madre, mi amante, mi hermana, todo a la vez, la mentira hecha Hada, como dice Tennyson, el espectro de la realidad como la pinta Hugo. (HERRERA Y REISSIG, 1998, p. 402)

Como lhe é característico, a escritura de Herrera y Reissig opera com cascatas de ecos, associações e amplificações; permitamo-nos retalhar o texto. A primeira frase institui o discurso como advertência de um "eu" poeta a um "tu" leitor. A partir da segunda frase e quase até o fim da nota, desaparecem esses dêiticos, e o discurso corre como dissertação em defesa de um certo tipo de poesia. Na definição desse tipo, que é feita de forma oblíqua e por dispersão de atributos, confundem-se dois conjuntos: um abrange poetas de diversos idiomas e o outro se reduz aos poetas de língua espanhola.

O primeiro conjunto é o que poderíamos identificar como a poesia moderna internacional, e dentro dele há um grupo que pratica "literatura quintaesente". Observe-se aí que, 
ao usar o qualificativo "quintessente", Herrera y Reissig evita os rótulos correntes (parnasiana, decadente, simbolista, nefelibata, impressionista, torre-de-marfim etc.) em favor de uma palavra que dispara um paradigma indefinido: isto é, fica a cargo do leitor (do " $\mathrm{tu}$ ") elaborar uma lista mental de quais seriam os autores de literatura quintessente. A palavra sugere, é claro, uma direção: sugere pureza, perícia e um sentido de elevação acima da mediocridade, associando-se por exemplo aos preceitos da "Art poétique" de Verlaine ("De la musique avant toute chose... [...] et tout le reste est littérature", 1884, p. 2325) e de Mallarmé ("Donner un sens plus pure aux mots de la tribu", 1989, p. 99). Haveria, de um lado, os quintessentes e, de outro, todo o resto. Além disso, o texto da nota oferece outros parâmetros para a elaboração desse paradigma, como nomes de poetas que o integram: D'Annunzio e Samain. A doçura do primeiro, diz Herrera y Reissig, nasce das fontes sonhadoras da Paris poética; ao fazê-la representar diversos caracteres da música do verso proposta pela literatura quintessente ("sugiere, encanta, convierte la palabra en un murmurio, en un eco de crujía, en un pisar galante sobre pieles embrujadas"), o autor determina obliquamente a convergência de diversos empenhos da poesia contemporânea nas proposições francesas da segunda metade do século XIX. Por fim, aparecem também nomes de anteriores cabeçalhos do elenco da poesia lírica, sendo Safo a matriarca da dinastia e Hugo e Tennyson dois de seus mais recentes entronados, armando-se uma espécie de linhagem.

A diérese silenciada seria uma marca dessa moderna literatura quintessente, nomeadamente de Samain. Seu uso promove uma "elasticidade harmônica" e um "alongamento aristocrático da palavra"; ao empregá-la, o tradutor se une ao grupo dos que praticam literatura quintessente. Aqui entra o subgrupo de interesse voltado à situação histórica dos poetas de língua espanhola: uma das maiores conquistas da literatura quintessente teria sido converter em veludo e música (terciopelos del pentágrama) os metais (la plancha broncina, de bronze) e as rochas (pedrusco) da elocução poética tradicional. Herrera y Reissig age na tópica do que chamavam a anquilose do verso castelhano: como diversos poetas de seu tempo, acusa a poesia castelhana de se haver especializado em poucas formas, especialmente as adequadas para a representação de coisas públicas, heroicas, solenes etc., enrijecendo-se e rechaçando 
novidades. Ao participar com papel destacado na reforma poética, a diérese silenciada leva, por isso, o mérito de ser "o sereno encanto, a alma de moiré da música do verso". Vale lembrar aqui que a palavra moiré (em espanhol moaré, galicismo que designa uma espécie de tecido) se havia difundido como emblema modernista numa célebre aliteração onomatopaica que constava de um conto de Rubén Darío - "el raso y el moiré que con su roce ríen" -, destacada e discutida desde o prólogo de Eduardo de la Barra à primeira edição de $A z u l . . .$, em 1888.

Considerando as associações que vimos expondo, é possível afirmar que, quando Herrera y Reissig tinge com os matizes crepusculares da intimidade as cores claras ou primárias do discurso científico e da maquinaria bélica (a "catapulta épica" da poesia castelhana, que arroja sílabas duras e pesadas contra o ouvido do leitor), ele está escrevendo, alegoricamente, uma breve história do modernismo hispanoamericano - um dos nomes que poderia levar, então, essa facção hispânica da literatura quintessente. Herrera y Reissig evita aí o uso de qualquer rótulo, não para cobrir de nuvens o assunto, nem para se desligar deste ou daquele movimento, mas talvez para poder tratar a questão com mais qualificativos do que substantivos: ou seja, para ser mais preciso, para descrever com mais apuro o que não vê vantagem em definir, e para reduzir o risco de que sua defesa da diérese silenciada seja interpretada a partir daqueles rótulos, nem por quem insiste em usá-los.

A segunda nota de rodapé que Herrera y Reissig escreveu em defesa da diérese silenciada se refere ao seguinte verso de sua tradução do poema "Nina", de Zola: "Basta para la sonrisa y el ensueño de un día" (1998, p. 416). A dificuldade aí seria a escansão do segundo hemistíquio: para chegar às oito sílabas, é preciso ler ensueño com diérese ou de un día sem sinalefa. Prevenindo possíveis censuras ao verso, o tradutor puxa esta nota de advertência, que começa remetendo à nota anterior:

Léase mi nota [...] sobre la magnífica importancia de la diéresis en la métrica moderna. Los que están acostumbrados a los versos de fierro, a los apeñuscamientos diptónguicos, que constituyen el pedregal de quienes versifican en España y en estos pueblos, no me lean si de antemano no se proponen con abstracción de rutinas, adaptar su oído al terciopelo melódico de la palabra dulcificada. Hallo innecesario el signo cursi, a modo de licencia, de los dos puntillos sobre la vocal, desde 
que a mi sentir un lector culto, que se dé cuenta del arte y del refinamiento de la expresión, no necesita señales que lo adviertan del valor fónico y de las curvas que sugiere cada vocablo, luego que el Poeta los acaricia. [...] (HERRERA Y REISSIG, 1998, p. 416, grifos do autor)

Agora o "eu" não se dirige a um "tu", mas contra um "eles": não me leiam aqueles que estão acostumados a metal e rocha (fierro, pedregal) e não se propõem a abstrair-se de suas rotinas de leitura. Essas rotinas remetem novamente à dureza da dicção. Os ditongos frequentes são uma característica do idioma (basta comparar com o português), mas os apeñuscamientos diptónguicos, os ditongos que se amontoam, constituem o pedregal daqueles que versificam em espanhol. Esse pedregal pode ser entendido pelo menos de duas formas: uma, é dele que os versificadores da tradição castelhana vêm colhendo as pedras que lançam de suas catapultas épicas; outra, é ele o terreno acidentado que o poeta moderno tem que saber transformar para obter o veludo melódico da palavra dulcificada... O ditongo é, pode-se dizer, uma pedra nos sapatos de veludo de Herrera y Reissig; e a diérese, tradicionalmente tomada como licença, torna-se um alívio para esse sofrimento. Quebrando as séries de ditongos, a diérese promove a transformação alquímica do material poético.

Para concluir, falta discutir um último ponto. Há coisas que só se podem conhecer obliquamente. Em suas duas notas de rodapé, Julio Herrera y Reissig não precisou citar versos alheios com o diacrítico para provar a existência deles, muito menos reproduzir fac-símiles de páginas velhas. Para nós, que o lemos hoje, a presença do sinal indicativo de diérese em versos publicados no século XIX é um dado que se prova suficientemente pela existência de um ataque a esse diacrítico publicado em 1903.

Quando listamos, no início deste texto, versos de Rubén Darío marcados com o diacrítico, pretendíamos apenas expor o mecanismo da diérese, para favorecer a compreensão do assunto; ainda assim, tomamos o cuidado de avisar que os transcrevíamos a partir de uma edição crítica (1968). Mas a escolha dessa edição trazia um prejuízo evidente: ela não foi lida por Herrera y Reissig, morto em 1910.

Como teriam aparecido esses mesmos versos de Darío em edições publicadas antes de 1910 ? O primeiro exemplo, extraído 
do poema "Cosas del Cid" (Prosas profanas), está grafado assim em sua primeira publicação em livro (1901):

Rodrigo de Vivar pasa, meditabundo,

Por una senda en donde, bajo el sol glorioso,

Tendiéndole la mano, le detiene un leproso.

(DARÍO, 1901, p. 139)

A palavra glorioso deve ser lida com diérese, embora não leve o diacrítico. O segundo exemplo, do poema "Melancolía", assim aparece na segunda edição (1907) de Cantos de vida y esperanza, Los cisnes y Otros poemas:

Ese es mi mal. Soñar. La poesía

Es la camisa férrea de mil puntas cruentas

Que llevo sobre el alma [...]

(DARÍO, 1907a, p. 133)

A palavra cruentas deve ser lida com diérese, embora não leve o diacrítico. No quarto exemplo, a palavra cruel, que deve ser lida com diérese, aparece sem diacrítico na edição de 1907 (p. 100) citada acima, e também sem diacrítico num manuscrito autógrafo do poema, reproduzido em fac-símile numa edição especial de 2004:

Rosa de dolor, gracia femenina;

Inocencia y luz, corola divina,

Y aroma fatal y cruel espina...

(DARÍO, 2004, p. 62)

Nessa edição de 2004 encontram-se outros quatro manuscritos em que Darío silenciou a diérese (p. 41, 55, 155 e 157), e nenhum em que apareça o diacrítico. Os organizadores do livro anotam que, de um total de cinco ocorrências, três passaram a grafar-se com o diacrítico a partir da terceira edição dos Cantos de vida y esperanza (Barcelona: Maucci, 1907) e outros dois apenas a partir da edição crítica de 1968 - na qual não há advertência alguma a respeito desses acréscimos.

Na vasta coleção de manuscritos de Darío abrigada pela Biblioteca Nacional do Chile, encontramos apenas uma vez o diacrítico escrito pela mão do poeta, justamente na palavra 
pöeta, no verso 9 de um poema inédito intitulado "Nox-Aurora": "Pero este Pöeta fue" (DARÍO, ms. 530, f. 1, s/d). Na mesma folha, porém, no primeiro verso do poema, a palavra poeta aparece sem o diacrítico, ainda que, por razões métricas, deva ser lida com diérese ("De algún poeta el delirio").

Quer dizer, então, que a diérese silenciada era comum em Darío, e que o sinal diacrítico só foi introduzido em seus versos por editores e revisores? É possível. Mas isto não significa que Herrera y Reissig tenha falseado a questão, lançando advertências virtualmente inúteis a respeito. Pelo contrário. Em suas notas, ele não reclama para si a invenção da diérese silenciada; apenas faz dela o ponto de partida, como vimos, para a defesa de uma série de recursos capazes de promover, em conjunto, uma nova música para a poesia em língua espanhola, trocando os metais e as duras pedras do estilo predominante na tradição castelhana pelas sutilezas "de veludo e moiré" da poesia contemporânea. Pode-se dizer que a presença do diacrítico significava, para Herrera y Reissig, a presença da instituição normatizadora, da polícia da língua; um indesejável imprimatur manchando a página de academicismo, e transformando em licença poética, permitida por terceiros, algo que deveria ser interpretado como elemento estruturante da música do verso. Nesse sentido, o uso da diérese silenciada não devia passar despercebido: a ausência do diacrítico marca um gesto deliberado de apagamento, tornando-o portanto presente no texto. Daí as notas tão abrangentes.

Então a pesquisa só deveria levar em conta os manuscritos autógrafos? Neste caso, não. Já que o diacrítico indicador da diérese é uma norma voltada a instruir os leitores de um livro sobre como escandir os versos, mais vale buscá-lo nas versões impressas destinadas a um público presumivelmente mais amplo do que em manuscritos de circulação restrita. Em manuscritos, a ausência ou presença do diacrítico pode informar algo sobre a vontade do autor e sobre seus hábitos de escriba; em revistas e livros publicados, informa sobre uma prática poética em sentido amplo, incluindo a participação de editores, revisores e tipógrafos na constituição do texto final. A ausência sistemática do diacrítico em alguns dos primeiros livros de Darío mostra que silenciar a diérese era algo possível, em espanhol, na primeira década de 1900; sua presença em outros mostra que assinalá-la também o era. E sua presença 
massiva na edição crítica de 1968 mostra que o editor Méndez Plancarte optou por normatizar as grafias de acordo com parâmetros de seu tempo presente (a mesma opção que leva quase todos os editores a atualizar a pontuação e a ortografia de textos anteriores ao século $X X$, por exemplo).

Por último, a pesquisa só pode ser feita com base na primeira versão publicada de um livro ou poema, ou de uma edição princeps etc.? Neste caso, isto tampouco vale como regra, dadas a quantidade e a qualidade das variantes encontradas. $\mathrm{O}$ desprezo pelas variantes levaria o pesquisador a omitir dados importantes. Por exemplo: a primeira publicação do soneto “El almuerzo", de Julio Herrera y Reissig, em 1904, trazia um verso com diérese silenciada ("Un cielo bondadoso y un céfiro tierno...", El Diario Español, apud HERRERA Y REISSIG, 1998, p. 104); mas na segunda, feita um ano depois, a métrica aparece retificada pela substituição de "céfiro" por "cefirillo": "Un cielo bondadoso y un cefirillo tierno..." (HERRERA Y REISSIG, 1914, p. 19), e essa emenda tem sido adotada em diversas edições do poema em livro, desde a de 1914, cuidada por Rufino Blanco-Fombona.

As notas de Herrera y Reissig sobre a diérese silenciada cumprem, então, uma função tática que vai muito além da discussão técnica e normativa. Ensejam a percepção de que o ritmo poético não está plenamente inscrito no texto, como tampouco independe dele: produz-se historicamente em construtos complexos, nos quais interferem diversos membros de uma sempre dinâmica comunidade que inclui poetas, leitores, editores, preceptistas. Dessa perspectiva, haveria sempre uma política do verso. E, nos anos do Modernismo hispano-americano, parece justo descrever a participação dos poetas de que nos ocupamos como um esforço - nesse sentido, coordenado - pela ampliação do sufrágio versificatório para fora do círculo normativo baseado em antecedentes castiços da tradição, representado no controle desempenhado pelos acadêmicos da Real Academia Española e de outras autoridades literárias como os poetas e professores reunidos em sociedades ateneístas na América. "Ama tu ritmo y ritma tus acciones / bajo su ley, así como tus versos", predicava Rubén Darío (1968, p. 617) aos jovens, divulgando uma prática em que as balizas estanques da versificação já não poderiam substituir por decreto o papel ativo da comunidade leitora e produtora na apreciação da poesia, uma vez que o pedal do poeta poderia esfumar os 
limites antes nítidos e exigir uma disposição geral à novidade e à expressão. Enquanto Herrera y Reissig, na contramão dos tratados científicos e positivos que buscavam descobrir as leis do ritmo, escrevia em 1905 que o único problema para o poeta era "el desconocido irreductible que está [...] en el ritmo de todas las leyes" (HERRERA Y REISSIG, 1998, p. 598).

\section{REFERÊNCIAS}

ÁLVAREZ, Mario. Ensueño y delirio: vida y obra de Julio Herrera y Reissig. Montevideo: Academia Nacional de Letras, 1995.

DARÍO, Rubén. Azul... Prólogo de E. de la Barra. Valparaíso: Imp. y Lit. Excelsior, 1888.

. Cantos de vida y esperanza, Los cisnes y Otros poemas. 2.ed. Madrid: F. Granada y Cía., 1907.

. Poesías. Ed. facsimilar y con variantes. México: Fondo de Cultura Económica, 2004.

Poesías completas. Ed. A. Méndez Plancarte. 11 ed. Madrid: Aguilar, 1968.

. Prosas profanas. 2 ed. Paris: Vda de Ch. Bouret, 1901.

GÓMEZ de HERMOSILLA, Josef. Arte de hablar en prosa y verso. T.II. Madrid: Imprenta Real, 1826.

HERRERA y REISSIG, Julio. Los peregrinos de piedra. 3.ed. Prefacio de R. Blanco-Fombona. Paris: Garnier, 1914.

Poesía completa y prosas. Madrid/São Paulo: ALLCA XX / Scipione Cultural, 1998.

MALLARMÉ, Stéphane. Poésies. Ed. Lloyd James Austin. Paris: Flammarion, 1989.

MEJÍA SÁNCHEZ, Ernesto (Org.). Estudios sobre Rubén Darío. México: Fondo de Cultura Económica / Comunidad Latinoamericana de Escritores, 1968.

ROSEN, Charles. A geração romântica. Tr. Eduardo Seincman. São Paulo: Edusp, 2000. 
SAMAIN, Albert. Oeuvres de Albert Samain. Paris: Mercure de France, 1924.

VERLAINE, Paul. Jadis et Naguère. Paris: Léon Vanier, 1884.

\begin{abstract}
Julio Herrera y Reissig: Poetry with Pedals

In his explanatory notes regarding the solutions he adopted for the translation of two French poems, the Uruguayan poet Julio Herrera y Reissig (1875-1910) defends the use of the "silenced diaeresis", taking it as the starting point of a large proposition in favor of a new music of the verses. Through the concurrent employment of a series of specific resources, it would enable the promotion of a new music for poetry in Spanish. This essay argues that Herrera y Reissig's notes on this subject have a tactical function that goes far beyond technical and normative discussions, and may be interpreted as a prescription for and a description of the music of the so-called Modernist Hispanic-American poetry. His notes lead to the perception that the poetic rhythm is not wholly inscribed in the text, but not altogether independent of the text: it is produced historically, in complex constructs, with the intervention of various members of a constantly dynamic community including poets, readers, editors, scholars.
\end{abstract}

Keywords: Julio Herrera y Reissig (1875-1910), Silenced diaeresis, Hispanic-American Modernism, Music and Poetry, Rhythm. 